\title{
El embargo en
}

materia fiscal federal:

entre la legalidad

y la falta de límites*

/ The embargo

on federal Tax matters

between legality

and the lack of limits

* Recibido: 5 de junio de 2014. Aceptado: 9 de julio de 2014.

Tla-MelauA, revista de Ciencias Sociales. Facultad de Derecho y Ciencias Sociales. Benemérita Universidad Autónoma de Puebla, México / IssN: 1870-6916 / Nueva Época, Año 8, No 37, octubre 2014 / marzo 2015, pp. 156-184. 
Eric Sergio Revilla Cerrillo* Ana del Carmen Soto Amador**

\section{RESUMEN}

Ante la existencia de un crédito fiscal firme a favor de la federación, nace un estado de inseguridad objetiva y subjetiva respecto al patrimonio del contribuyente, pues ante el cobro del adeudo vía embargo de bienes por parte de la autoridad fiscal, si bien esta última sólo puede embargar hasta el límite del adeudo, el ejecutor actuante en ejercicio de una facultad reglada e ilimitada, y de manera subjetiva, valiéndose sólo de su juicio y no del monto adeudado o de los documentos mostrados por terceros, embarga los bienes que quiera y no los que deban ser; facultad reglada, discrecional, arbitraria o subjetiva por indeterminada, pero a final de cuentas un acto de legalidad sin límites.

PALABRAS CLAVE

Ejecutor, embargo, juicio, subjetividad, límites.

\section{A B S T RAC T}

In the presence of a strong tax credit in favor of the federation, a state born of objective and subjective uncertainty about the property of the taxpayer, therefore, faced with the collection of the debt via garnishment the taxpayer estate, executed by the tax authority. Granted that the latter can seize to the limit of the debt, the executor acting in the exercise of the circumscribed and unlimited power awarded, subjectively, using merely the opinion of the executor and not the amount owed or the documents presented by third parties, seizes personal property to suit the executor and not what should be; capability regulated discretionary, arbitrary or a subjective power without limits, ultimately an act of legality with limits.

KEYWORDS

Executor, garnishment, judgment, subjectivity, limits.

\footnotetext{
* Profesor del posgrado de la Facultad de Derecho y Ciencias Sociales de la Benemérita Universidad Autónoma de Puebla (BUAP), México. (dr_sergiorevilla@hotmail.com)

** Doctorante del posgrado de la Facultad de Derecho y Ciencias Sociales de la Benemérita Universidad Autónoma de Puebla (BUAP), México. (anasotoamador@gmail.com)
} 
1. Introducción / 2. El procedimiento administrativo de ejecución (PAE) / 3. El embargo en materia fiscal / 4. El aseguramiento de bienes sin límites / 5. El juicio de la autoridad / 6. En busca de explicaciones / 7. La indefinición del acto / 8. Conclusiones

\section{INTRODUCCIÓN ${ }^{1}$}

El discurso mediático de las instituciones del estado federal, respecto a la situación económica del país, intenta ser alentador; sin embargo, las personas que nos rodean opinan lo contrario. Existe una contradicción entre lo que dicen las instituciones del Estado y lo que realmente se percibe.

Dependiendo del papel que se tiene en el engranaje económico social y la perspectiva de cada persona, se atribuye a diversas causas, principalmente la situación económica que se vive hoy en día en lo individual y en lo colectivo. Sin embargo, si en algo coinciden todos es en que una de las causas de la mala situación económica del país radica en las obligaciones de carácter fiscal que el Estado impone a la sociedad y que se reflejan en pagos cada vez mayores y en formas complejas de cumplirlas.

Si bien este contexto trae consigo la preocupación social de cómo hacer para que el dinero que genera el particular le permita cubrir necesidades primarias, que van desde la supervivencia de empresas hasta la alimentación de las personas, también trae consigo el miedo generalizado de perder el patrimonio y, en algunos casos, hasta la libertad, derivado de los pasivos que las personas tanto físicas como morales tienen, como resultado del incumplimiento de obligaciones ante el fisco.

Analizando la naturaleza jurídica del fisco en el plano normativo, vemos que desde la Constitución Política de los Estados Unidos Mexicanos, en su artículo 31 fracción IV, se establece que es obligación de los mexicanos contribuir al gasto público de la Federación, del Distrito Federal o del estado o municipio en que residan, de manera proporcional y equitativa como lo dispongan las leyes vigentes para tal efecto.

\footnotetext{
${ }^{1}$ Las reflexiones contenidas en este artículo se fundamentan no sólo en la investigación bibliográfica, sino también en la observación personal y la experiencia de los autores que en distintas ocasiones, durante los años 2011, 2012 y 2013, estuvimos presentes en diligencias de embargo llevadas a cabo por las autoridades fiscales federales y nos percatamos de la recurrencia del tema materia del presente documento.
} 
La Ley orgánica de la Administración Pública Federal establece, en su artículo 31, que le corresponde a la Secretaría de Hacienda y Crédito Público regir en materia financiera a nivel federal. Atendiendo a las potestades otorgadas, ésta creó el Servicio de Administración Tributaria como un órgano desconcentrado con una serie de normas que regulan su actuar.

El Código Fiscal de la Federación, una de las leyes más en importantes en materia fiscal federal, regula, entre otras cosas, el procedimiento de cobro de créditos (adeudos) fiscales que tienen los contribuyentes con la federación, representada por el Servicio de Administración Tributaria.

Son multifactoriales las razones por las cuales los ciudadanos no pagan sus contribuciones; como consecuencia, el Estado cobra de manera coactiva a través del procedimiento administrativo de ejecución, regulado en el Código Fiscal de la Federación.

Este procedimiento de cobro se desarrolla en una serie de etapas encaminadas a obtener el pago de un crédito fiscal o asegurar su cumplimiento mediante el embargo de bienes. El procedimiento económico coactivo inicia con el requerimiento del pago del adeudo; en caso de no finiquitarse en el momento, se aseguran los bienes que servirán para cubrir el monto del adeudo, los cuales, por último, se rematan para cubrir el crédito fiscal con el producto.

Ante la existencia de un crédito fiscal firme y exigible, el particular, con el ánimo de no pagar, hace uso de los medios de defensa disponibles en materia fiscal y trata de aprovechar las inconsistencias legales que tengan los actos de autoridad que sirven de base para el cobro (aspectos de fundamentación y motivación) y algunas otras lagunas de la ley. Sin embargo, este manejo de la norma, en cuanto a su interpretación y alcances a conveniencia, no es exclusivo de los contribuyentes, también la autoridad fiscal se sirve de ello. En este caso, el Código Fiscal de la Federación contempla diversas facultades subjetivas utilizadas por la autoridad fiscal para realizar sus actos, subjetividades en las cuales centramos el presente estudio, principalmente aquéllas contempladas en el embargo, por ser una parte sensible para los particulares.

Si bien las autoridades fiscales cuentan con facultades discrecionales y regladas que norman todos sus procedimientos, también la ley textualmente les permite realizar juicios de valor de manera subjetiva, actos que podrían calificarse de arbitrarios, pero que así están contemplados en la ley. Ante esas circunstancias, vale la pena preguntarnos: ¿es culpa de la autoridad fiscal, si a fin de cuentas actúa con apego a la ley? ¿Es culpa del legislador, que por descuido así lo estableció? ¿Lo establece la norma a propósito para velar por los intereses del Estado por encima de los particulares? 


\section{El procedimiento administrativo de ejecución (PAE)}

En materia fiscal, hay diversas causas por cuales nace a la vida jurídica un crédito fiscal, desde una multa por el incumplimiento tardío de una obligación tributaria hasta el resultado de una auditoría por parte de la autoridad hacendaria con motivo del ejercicio de sus facultades de comprobación.

Una vez que el crédito fiscal está determinado y es exigible por parte de la autoridad fiscal, ésta lo cobra a través del procedimiento administrativo de ejecución (PAE), de ejecución forzosa, que consiste en el "conjunto de actos que realiza la autoridad fiscal con la finalidad de obtener el cobro de los créditos fiscales adeudados por los contribuyentes" 2 o su garantía.

La doctrina describe al PAE como un "procedimiento a través del cual las autoridades fiscales, ante la inobservancia de las obligaciones por parte del contribuyente, exigen su cumplimiento sin necesidad de que exista sentencia previa de un órgano jurisdiccional". Esta figura jurídica se materializa cuando la autoridad hacendaria, en el ejercicio de sus facultades, determina un crédito fiscal a un contribuyente y al momento de ser exigible adquiere la calidad necesaria para que requiera su cobro al deudor. ${ }^{3}$

El Estado, a través de este procedimiento especial y sumario, puede exigir coactivamente el pago de las obligaciones tributarias cuando se descubre que el sujeto pasivo principal (contribuyente) o el responsable solidario de la obligación no cumplieron de manera espontánea con las mismas o que lo hicieron fuera de tiempo.

Jesús Quintana Valtierra sostiene que el procedimiento económico coactivo consiste en la serie de actos realizados por el Estado a fin de proceder coercitivamente en contra de los contribuyentes que no han cumplido voluntariamente sus obligaciones fiscales dentro del plazo fijado por la ley. Asimismo, cita a Miguel Fenech, quien define el procedimiento que nos ocupa como el medio jurídico con el cual se logra la satisfacción del acreedor cuando ésta no se obtiene a través de la prestación del deudor y es necesario conseguir aquella satisfacción independientemente de la voluntad del obligado y venciendo toda su contraria voluntad. ${ }^{4}$

El PAE, en materia fiscal federal, se encuentra regulado en el Código Fiscal de la Federación (CFF), específicamente en el título v: De los Procedimientos Administrativos, Capítulo III: Del Procedimiento Administrativo de Ejecución, del artículo 145 al 196-B. ${ }^{5}$

\footnotetext{
${ }^{2}$ Quintana Valtierra, Jesús y Rojas Yáñez, Jorge, Derecho Tributario Mexicano, México, Trillas, 2002, pp. 207 y 208.

${ }^{3}$ Jiménez González, Antonio, Lecciones de Derecho Tributario, 10a Edición, México, cengage Learning, 2009, pp. 405-406.

${ }^{4}$ Quintana Valtierra, Jesús y Rojas Yáñez, Jorge, op. cit., pp. 207 y 208.

${ }^{5}$ Para efectos del presente artículo, se realizan algunas consideraciones respecto al tema materia de
} 
Dicho ordenamiento establece que si los créditos fiscales no son cubiertos en la fecha o plazos que la ley señala para tal efecto, éstos pueden ser requeridos por las autoridades fiscales a través del PAE, pues su única finalidad es que se cubra el monto del crédito principal con el producto de los bienes que sean embargados.

Hablar de la naturaleza del PAE conlleva a recordar que es un procedimiento, es decir, un conjunto de trámites para llegar a la elaboración de un acto; es una coordinación de actos que se ponen en marcha y se relacionan con los efectos jurídicos que producen como parte de un proceso. Se define proceso administrativo como "el cauce legal que los órganos de la administración se ven obligados a seguir en la realización de sus funciones y dentro de su competencia para producir los actos administrativos" ${ }^{6}$

El procedimiento que nos ocupa busca el pago del crédito fiscal que tiene el contribuyente con el fisco federal, a través de etapas sucesivas para que, una vez efectuado el embargo de bienes del deudor y el remate, el producto se aplique a cubrir el adeudo. Así, los actos administrativos que componen el procedimiento administrativo de ejecución, se encuentran en el cFF y se clasifican de la siguiente forma: a) Actos de iniciación: requerimiento de pago; b) Actos de desarrollo: embargo; y c) Actos de conclusión: remate de bienes embargados y aplicación del producto al crédito.

\section{EL EMBARgO EN MATERIA Fiscal}

Los actos procedimentales encaminados a conseguir el desenvolvimiento del procedimiento de cobro se denominan actos de desarrollo. En el caso del PaE, el acto de desarrollo es el embargo.

El embargo es el conjunto de actividades cuya principal finalidad es afectar bienes concretos del patrimonio del deudor a una ejecución procesal frente a él dirigida. ${ }^{7}$

La Enciclopedia Jurídica Mexicana señala que el embargo puede ser definido como "la afectación decretada por una autoridad competente sobre un bien o conjunto de bienes de propiedad privada, la cual tiene por objetivo asegurar cautelarmente la eventual ejecución de una pretensión de condena que se plantea o planteará en un juicio o bien satisfacer directamente una pretensión ejecutiva". ${ }^{8}$

análisis, desde la perspectiva fiscal federal, al amparo del procedimiento regulado en el Código Fiscal de la Federación.

${ }^{6}$ LóPez Nieto, Francisco, El procedimiento administrativo, 2a ed., Barcelona, Bosch, 1946, p. 2.

${ }^{7}$ Diccionario Furídico Espasa, España, ESPASA Siglo XXI, 2002, p. 631.

${ }^{8}$ Instituto De Investigaciones Jurídicas-unam, Enciclopedia Furídica Mexicana, tomo 3, 2a ed., México, Porrúa, 2004, p. 708. 
En el derecho tributario, el embargo de bienes es una fase del procedimiento de recaudación que se encuadra en el periodo ejecutivo, dentro del procedimiento de apremio, cuando el obligado tributario no paga la deuda en el plazo fijado tras la notificación de la providencia de apremio. Su finalidad es procurar el cobro de la prestación tributaria y los gastos del proceso con la suma obtenida de rematar los bienes embargados. ${ }^{9}$

El ordenamiento jurídico mexicano en materia fiscal, GFF, destina una sección especial al embargo como parte del procedimiento administrativo de ejecución. Del numeral 151 al 163, se describe la forma en la que se desarrolla el embargo dentro del PAE y la casuística del embargo sobre bienes muebles, inmuebles, negociaciones y depósitos bancarios, por mencionar los más destacados.

A continuación se abordarán los aspectos más importantes del embargo, excluyendo los supuestos y características del embargo precautorio y el embargo en la vía administrativa, por no estar relacionado de manera directa con el presente artículo.

Para que el embargo se pueda realizar, es necesario que se cumplan algunas condiciones previas:

- La existencia de una obligación a cubrir

- La notificación al contribuyente del crédito fiscal a su cargo

- Que haya concluido el plazo para el pago del crédito y no se haya cubierto

- Que se haya realizado el requerimiento de pago

- Que una vez hecho el requerimiento de pago, éste no se haya efectuado.

De acuerdo con el artículo 155 del Código Fiscal de la Federación, durante la etapa del embargo de bienes, intervienen tres sujetos:

a) El contribuyente deudor, el representante legal del contribuyente o la persona con quien se entiende la diligencia.

b) El ejecutor, nombrado para actuar y llevar a cabo esta parte esencial del PAE, mismo que es designado por el jefe de la oficina exactora y que pertenece a la Administración Central de Cobro Coactivo del Servicio de Administración Tributaria.

c) Los testigos designados por el deudor o, en caso de negativa, los designados por el ejecutor.

\footnotetext{
${ }^{9}$ Diligencia de requerimiento de pago y embargo de bienes del deudor fiscal. El acta respectiva debe especificar en forma circunstanciada, que se requirió la presencia del contribuyente o su representante legal, y que como no se les encontró, por no atender el citatorio previo, la diligencia se realizó por conducto de diversa persona. Semanario fudicial de la Federación y su Gaceta, tomo 23, México, scjn, Novena Época, Junio, 2006, p. 1151.
} 
En atención a lo que establece el artículo 152 del CFF, el lugar en donde se llevará a cabo el embargo es el domicilio fiscal del contribuyente deudor.

En la norma fiscal, el objetivo del embargo se establece en las fracciones I y II del artículo 151 del CFF, y resulta ser: embargar bienes suficientes para, en su caso, rematarlos, enajenarlos fuera de subasta o adjudicarlos en favor del fisco; y embargar negociaciones con todo lo que de hecho y por derecho les corresponda, a fin de obtener, mediante la intervención de ellas, los ingresos necesarios que permitan satisfacer el crédito fiscal y los accesorios legales.

Según Miguel Fenech, citado por Jesús Quintana Valtierra, el propósito del embargo es la determinación de los bienes que han de ser objeto de la realización forzosa, fijando su sometimiento a la ejecución, y que tienen como contenido una intimidación al deudor para que se abstenga de realizar cualquier acto dirigido a sustraer los bienes determinados y sus frutos como garantía del crédito. ${ }^{10}$

El objetivo primordial del embargo es hacer efectivo un crédito fiscal exigible y el importe de sus accesorios legales, entendiendo por estos últimos los recargos, sanciones y gastos de ejecución.

El artículo 155 del Código Fiscal de la Federación establece como objeto de embargo los bienes del deudor, siempre y cuando estos sean de fácil realización y venta, y el orden al que debe sujetarse el ejecutor para designar los bienes embargables. Al respecto, el CFF hace dos distinciones, ya que hay bienes que pueden ser susceptibles de embargo y otros que no.

En el mismo orden de ideas, el artículo 156 del Código indica los pasos que deberá seguir el ejecutor en caso de que se presenten supuestos que puedan impedir la realización del embargo, otorgándoles facultades para que logren la extracción de bienes del deudor que sirvan para cubrir el crédito fiscal, por lo tanto no habría razones por las cuales el embargo de bienes se viera obstaculizado o que no se llegara a cumplir con su objetivo primigenio.

El CFF hace una distinción importante: por un lado, indica los bienes que pueden ser susceptibles de embargo (artículo 155) y por otro, el artículo 157 indica los bienes que no pueden ser embargados, delimitación que atiende a la necesidad de proteger el patrimonio del deudor. Las consecuencias que se producirían al no establecer límites para el embargo podrían ser negativas al grado de causar un daño irreparable a los derechos reales del contribuyente.

Es importante aclarar que, una vez que los bienes hayan sido embargados, los derechos que se tienen sobre éstos pasan a manos de la autoridad hacendaria, quien a partir de ese momento tendrá la potestad real de disponer de ellos dentro de los fines estrictamente procesales a través de los procedimientos de enajenación, adjudicación o administración y remate.

${ }^{10}$ Quintana Valtierra, Jesús y Rojas Yáñez, Jorge, op. cit., p. 253. 


\section{El aseguramiento De Bienes Sin Límites}

Uno de los reclamos más recurrentes de los contribuyentes que tienen adeudos fiscales que son exigibles son los excesos en que incurren los ejecutores a la hora de llevar a cabo un embargo con el objeto de garantizar un crédito fiscal u obligar al contribuyente deudor a su pago en ese momento. Estos excesos, en apariencia, constituyen un abuso de autoridad.

Sin embargo, vemos que el Código Fiscal de la Federación permite a los ejecutores la posibilidad de actuar en la etapa de embargo, en apariencia sin límites, situación que resulta jurídicamente cuestionable y merece algunas reflexiones. Veamos lo que el Código Tributario señala al respecto:

Artículo 156.- El ejecutor podrá señalar bienes sin sujetarse al orden establecido en el Artículo anterior, cuando el deudor o la persona con quien se entienda la diligencia:

I. No señale bienes suficientes a fUICIO del ejecutor o no haya seguido dicho orden al hacer el señalamiento.

Artículo 157.- Quedan exceptuados de embargo:

$[\ldots]$

II. Los muebles de uso indispensable del deudor y de sus familiares, no siendo de lujo a fUICIO del ejecutor. En ningún caso se considerarán como de lujo los bienes a que se refieren las demás fracciones de este artículo, cuando se utilicen por las personas que, en su caso, las propias fracciones establecen. $[\ldots]$

IV. La maquinaria, enseres y semovientes de las negociaciones, en cuanto fueren necesarios para su actividad ordinaria a fUICIO del ejecutor, pero podrán ser objeto de embargo con la negociación en su totalidad si a ella están destinados.

Artículo 158.- Si al designarse bienes para el embargo, se opusiere un tercero fundándose en el dominio de ellos, no se practicará el embargo si se demuestra en el mismo acto la propiedad con prueba documental suficiente a fUICIO del ejecutor. La resolución dictada tendrá el carácter de provisional y deberá ser sometida a ratificación, en todos los casos por la oficina ejecutora, a la que deberán allegarse los documentos exhibidos en el momento de la oposición. Si a juicio de la ejecutora las pruebas no son suficientes, ordenará al ejecutor que continúe con la diligencia y, de embargarse los bienes, notificará al interesado que puede hacer valer el recurso de revocación en los términos de este Código. 
Todo acto administrativo, por mandato constitucional, debe estar debidamente fundado para dar certeza jurídica a los particulares sometidos a algún procedimiento por parte de una autoridad; no obstante, en este caso no estamos ante una actuación de autoridad (embargo) que no esté debidamente fundado y motivado, sino que es un acto que, derivado de la fundamentación que lo sustenta, genera incertidumbre al particular respecto al grado de afectación que tendrá su patrimonio.

Esto es así, pues basta que analicemos los artículos antes transcritos para arribar a conclusiones cuestionables en perjuicio del contribuyente, que no resultan ser culpa de la autoridad fiscal: a fin de cuentas, como dice un principio de derecho "las autoridades sólo pueden hacer lo que la ley les permite", y en este caso la ley no pone límites.

Es importante no perder de vista que el embargo de bienes se debe de realizar en proporción al importe del crédito fiscal, en términos de lo que establece la fracción I, del artículo 151 del CFF, ${ }^{11}$ lo cual debe de observar el ejecutor en todo momento de la diligencia. Sin embargo, la ley no marca límites a esa apreciación de la proporción que debe observar el ejecutor.

En la fracción I, del artículo 156 del Código Fiscal de la Federación, vemos que para garantizar el pago del crédito fiscal, al momento de la diligencia de embargo, el ejecutor, a su juicio, puede considerar que los bienes señalados para embargo por la persona con la que se entiende la diligencia no son suficientes y señalar más bienes; es decir, la ley le permite utilizar su juicio como único elemento para determinar el valor de los bienes embargados y su suficiencia en relación con el monto del adeudo, lo cual se traduce en el poder de embargar todos los bienes que quiera, sin que sea necesario que cuente con conocimientos técnicos o periciales.

En las fracciones II y IV del artículo 157 del CFF, se establece que quedan exceptuados de embargo los bienes que a juicio del ejecutor sean de uso indispensable del deudor y de sus familiares y los bienes necesarios para su actividad ordinaria. Lo anterior implica que el ejecutor, en el momento de la diligencia de embargo, determina qué bienes son indispensables para el deudor y sus familiares, y puede caer en los extremos de embargar enseres básicos o fundamentales para la sobrevivencia de éstos si así lo decide. De igual forma, la ley no obliga al ejecutor a tener algún conocimiento especializado sobre cuáles son los bienes necesarios para la actividad ordinaria del deudor, pues aun teniendo el contribuyente una actividad muy básica (alba-

\footnotetext{
11 "Artículo 151. Las autoridades fiscales, para hacer efectivo un crédito fiscal exigible y el importe de sus accesorios legales, requerirán de pago al deudor y, en caso de que éste no pruebe en el acto haberlo efectuado, procederán de inmediato como sigue: I. A embargar bienes suficientes para, en su caso, rematarlos, enajenarlos fuera de subasta o adjudicarlos en favor del fisco, o a embargar los depósitos o seguros a que se refiere el artículo 155, fracción I del presente Código, a fin de que se realicen las transferencias de fondos para satisfacer el crédito fiscal y sus accesorios legales. II...."
} 
ñil, plomero, carpintero, etcétera), el ejecutor puede exceptuar de embargo sólo un desarmador o un martillo (v. gr.) por considerar que es lo necesario para el deudor, sin saber si su actividad es más compleja o especializada.

Si bien la esencia de las fracciones II y IV del artículo 157 del cFF es que el deudor y sus familiares, derivado de un embargo, no queden sin los bienes básicos para su subsistencia y para realizar sus actividades primarias. La forma en que se encuentra redactado el precepto en comento da la posibilidad al ejecutor de privar al deudor de esos medios mínimos de subsistencia.

El artículo 158 del cFF establece que si en el momento de una diligencia de embargo un tercero se opusiere argumentando el dominio de los bienes, no se practicará el embargo si se demuestra con prueba documental suficiente la propiedad de los bienes a juicio del ejecutor. Es de explorado derecho que la propiedad de un bien no siempre se acredita con una factura o una escritura de compraventa; quizá sean los medios más comunes; sin embargo, si un mueble es de procedencia extranjera, su propiedad se acreditará con documentos diferentes a los que estamos acostumbrados a ver, o también se puede acreditar la propiedad de un bien, en la casuística, con un contrato de fideicomiso, una carta de crédito, un contrato de llave en mano o de arrendamiento financiero, documentos que, aun siendo legales, si escapan del entendimiento del ejecutor, no se podrán acreditar en el momento que la propiedad de los bienes a embargar pertenece a un tercero y pasarán a posesión del fisco.

En el caso descrito en este artículo, durante una diligencia de embargo, un tercero, que no es el deudor, puede salir afectado en su patrimonio si el ejecutor en funciones no cuenta con los conocimientos necesarios para identificar un documento que acredite la propiedad de un bien poco común.

\section{EL JUICIO DE LA AUTORIDAD}

En párrafos anteriores, se han comentado los preceptos legales que establecen una facultad aparentemente sin límites del ejecutor cuando a su juicio, al momento de una diligencia de embargo, tiene que determinar situaciones de suma importancia para el contribuyente respecto de su patrimonio. Pero ¿cuáles son o deben ser los alcances de ese juicio?

La palabra juicio deriva del latín judicium (de judex). Juicio, facultad o acción de juzgar; sentencia, decisión, acto del juez; opinión, parecer, dictamen; acción judicial, proceso, acusación, defensa; los mismos magistrados en sala de justicia; el lugar en que la administra, tribunal; juicio, discernimiento, gusto; recompensa; testamento. ${ }^{12}$

${ }^{12}$ De Miguel, Raimundo, Nuevo diccionario latino-español etimológico, $2^{\mathrm{a}}$ ed., Madrid, Visor Libros Runes, 2013, p. 502. 
Haciendo de lado los aspectos jurisdiccionales, la palabra juicio, en la parte que nos interesa, implica decisión, opinión (sinónimo de juicio), ${ }^{13}$ parecer o gusto.

La filosofía señala que juicio es el acto mental de afirmar o negar un contenido asertivo. Tradicionalmente, se dice que un juicio afirma o niega un predicado de un sujeto. Tal como ha sido generalizada por los lógicos modernos, esta afirmación o negación es siempre la de una relación (no necesariamente la de una predicación) entre unos términos (no necesariamente dos). ${ }^{14}$

En esencia, desde el punto de vista filosófico, juicio es la posición de afirmar o negar un elemento asertivo, posición que está lejos de establecer parámetros que nos permitan estar en un plano justo de las cosas.

Desde el punto de vista psicológico, juicio es el acto mental de relacionar dos conceptos, acompañado por la fe o afirmación de alguna relación objetiva o intrínseca entre ambos; dicho significado es usual en la lógica formal. En un criterio más frecuente en psicología y lógica modernas, la palabra juicio se refiere a la aplicación de un concepto a una situación u objetos determinados, lo cual implica incluir apreciación de una situación, comparación (en la que se aplica el concepto de mayor o menor) y valoración (en la que se hace referencia a una serie de normas de belleza, justicia, bondad o valor económico). La expresión de un juicio en palabras se llama proposición..$^{15}$

Respecto a la palabra juicio, la Enciclopedia Jurídica Omeba nos señala dos acepciones: la primera, como una estructura lógica de pensamiento con pretensión de verdad; la segunda, con un sentido jurídico en el que el vocablo puede aludir a la operación mental previa que realiza el juzgador para emitir sentencia en un proceso o al proceso mismo. ${ }^{16}$

Con base en el párrafo anterior, jurídicamente la palabra juicio también implica una operación mental que, en este caso, busca la verdad o la emisión de una sentencia.

De lo analizado respecto al concepto de juicio, vemos que de los distintos significados no se desprende que tenga características objetivas, elemento y alcances en el uso del término que nos den certeza cuándo es utilizado en el Código Fiscal de la Federación como un elemento de valoración en el momento del embargo.

Así las cosas ¿estamos ante actos de autoridad reglados, discrecionales, arbitrarios o ante un desvió de poder?

\footnotetext{
${ }^{13}$ Remo, Guardia, Diccionario Porrúa de Sinónimos y Antónimos, 16 a ed., México, Porrúa, 2003, p. 208.

${ }^{14}$ D. Runes, Dagobert, Diccionario de filosofía, $2^{\text {a }}$ ed., Barcelona, Grijalbo, 1978, p. 210.

${ }^{15}$ Warren, Howard C. (compl.), Diccionario de psicología, $3^{a}$ ed., $10^{a}$ reimp., México, Fondo de Cultura Económica, 2010, p. 193.

${ }^{16}$ Enciclopedia furídica OMEBA, Tomo xxv, Buenos Aires, Driskill, 2000, p. 111.
} 


\section{EN BUSCA DE EXPLICACIONES}

Como hemos visto, la autoridad fiscal, al momento de realizar un embargo, hace uso de un juicio de valor que, en apariencia, no tiene límites, principalmente en el plano jurídico. Sin embargo, en busca de una explicación a este fenómeno, es procedente realizar un análisis de otros conceptos que pudieran estar relacionados.

\subsection{Facultades regladas}

En un país como México, los órganos que forman parte de la administración pública tienen la obligación de ceñir su actuación a lo que la norma jurídica establece, con la finalidad de preservar el estado de derecho. A través de las facultades regladas o vinculadas, el Estado lleva a cabo sus actuaciones con sustento en el ordenamiento jurídico vigente que las prevé. Este tipo de normas especifican lo que el órgano debe de hacer en el caso concreto sin admitir alguna variación en la ejecución de dicha potestad.

El Diccionario de la Real Academia de la Lengua Española define la palabra reglado/da como el adjetivo "dicho comúnmente del ejercicio de autoridad pública cuando las disposiciones vigentes no lo han dejado al discrecional arbitrio de ésta. Sujeto a precepto, ordenación o regla". ${ }^{17}$ Por lo tanto, se puede decir que las facultades regladas son las que están contenidas en el ordenamiento legal vigente y son contrarias a lo discrecional.

Manuel María Diez, en su Manual de Derecho Administrativo, indica que las facultades de un órgano están regladas cuando una norma jurídica predetermina una conducta específica que el órgano debe seguir; en el caso de la actividad reglada, la administración realiza una fiel ejecución de la ley que señala la autoridad competente, el fin, la forma del acto y cómo y cuándo ha de actuar. La ley predetermina a la administración lo más conveniente al interés público, supuestos en los cuales el administrador debe obedecer la ley y prescindir de su apreciación personal respecto al mérito del acto. ${ }^{18}$

Los siguientes son elementos de los cuales los actos administrativos reglados no pueden prescindir, pues su ausencia traería como consecuencia la invalidez de aquéllos.

a) Competencia.- Este elemento se traduce en la potestad que tiene la autoridad para dictar el acto.

\footnotetext{
${ }^{17}$ Diccionario de la Lengua Española, 22 a ed., Madrid, Real Academia de la Lengua Española, 2001. [Consulta: 20 de julio de 2014]. Disponible en: http://www.rae.es.

${ }^{18}$ María Diez, Manuel, Manual de Derecho Administrativo, tomo 2, Buenos Aires, Editorial Plus Ultra, 1981, p. 54 .
} 
b) Forma.- Establece la manera en la que se ha de exteriorizar la voluntad del agente que lleva a cabo el acto administrativo.

c) Procedimiento.- Se traduce en el conjunto de formalidades y actos que preceden y preparan el acto administrativo. ${ }^{19}$

Las facultades regladas de las autoridades administrativas se encuentran establecidas en un ordenamiento jurídico vigente, en las cuales la autoridad únicamente está autorizada para actuar como el texto de la ley lo indica, sin opción a interpretación o abstención de aplicar la ley. De igual forma, pueden ser calificadas las disposiciones normativas que especifiquen la competencia de la autoridad, el procedimiento que debe seguir, y la forma y objeto del acto que llevarán a cabo.

Cuando nos referimos a facultades regladas, no cabe la subjetividad del funcionario que lleva a cabo algún acto de autoridad, como un embargo, pues las facultades regladas indican claramente el sentido en que debe de emitirse y ejecutarse. Esta circunstancia está prevista de manera evidente en el texto normativo y señala el momento y sentido en que ha de producirse, el supuesto en el que se debe obedecer la ley y prescindir de apreciación personal respecto del acto. Por lo cual se insiste: un acto en el que impera para su realización una apreciación personal (subjetiva) no puede considerarse un acto reglado.

\subsection{Facultades discrecionales}

La actividad administrativa puede ser clasificada de diversos modos de acuerdo con las formas jurídicas que pueda asumir. Cada clasificación responde a diversas finalidades y explica las particularidades del ejercicio de la función administrativa.

Para comprender el sentido de las facultades discrecionales es preciso dar una primera aproximación del significado de la palabra discrecionalidad. La Real Academia de la Lengua Española define a la discrecionalidad como "la cualidad de lo discrecional, es decir, lo que se hace libre y prudencialmente, así como la potestad gubernativa en las funciones de su competencia que no están regladas". ${ }^{20}$ Como se puede observar, a partir de esta definición inferimos que lo discrecional está relacionado con la libertad de actuar, dentro del ámbito de su competencia.

\footnotetext{
${ }^{19}$ PAlacios Ibarra, Juan Francisco, "El control de la discrecionalidad administrativa". Revista furídica Online de la Facultad de Furisprudencia la Universidad Católica de Santiago de Guayaquil, Quito, agosto, 2001. [Consulta: 21 de julio de 2014]. Disponible en: http://goo.gl/SoflbX

${ }^{20}$ Diccionario de la Lengua Española, $22^{\mathrm{a}}$ ed., Madrid, Real Academia de la Lengua Española, 2001. [Consulta: 20 de julio de 2014]. Disponible en: http://www.rae.es.
} 
Por otra parte, la Enciclopedia Jurídica Mexicana señala que una facultad discrecional es el poder de libre apreciación que la ley reconoce a las autoridades administrativas sobre el contenido de sus actos o de sus acciones. Esta libertad, autorizada por la ley, puede ser de mayor a menor rango y resulta visible cuando la autoridad tiene la elección entre dos decisiones. ${ }^{21}$

Diversos especialistas en materia administrativa ofrecen algunas definiciones acerca de las facultades discrecionales de la administración.

Para Miguel Acosta Romero, una facultad discrecional "consiste en la facultad que tienen los órganos del Estado para determinar su actuación o abstención y, si deciden actuar, qué límite le darán a su actuación y cuál será el contenido de la misma; es la libre apreciación que se le da al órgano de la administración pública, con vistas a la oportunidad, la necesidad, la técnica, la equidad, o razones determinadas, que puede apreciar circunstancialmente en cada caso, todo ello, con los límites consignados en la ley", pues ésta determina formalmente el ámbito de competencia del órgano administrativo. ${ }^{22}$

Respecto a los actos discrecionales, Gabino Fraga sostiene que "el acto discrecional tiene lugar cuando la ley deja a la administración un poder libre de apreciación para decidir si debe obrar o abstenerse, en qué momento debe obrar, cómo debe obrar o qué contenido va a dar a su actuación. Por lo general, de los términos mismos que utilice la ley podrá deducirse si concede a las autoridades una facultad discrecional. Así, normalmente cuando la ley utilice términos que no sean imperativos sino permisivos o facultativos se estará frente al otorgamiento de un poder discrecional". ${ }^{23}$ Cabe aclarar que este tipo de términos no implican una obligación, sino que permiten o consienten.

Especialistas de otros países en materia administrativa también hacen algunas acotaciones al respecto. María José Alemán Pardo, colaboradora de la Fundación Mariano Ruiz-Funes, en Murcia, España, señala que la discrecionalidad es la facultad de la administración de actuar libremente cuando la ley da la habilidad para ello. Esta facultad surge cuando el ordenamiento jurídico atribuye a algún órgano la competencia para apreciar en un supuesto dado lo que sea de interés público. Dentro de la actividad de la administración pública, podemos distinguir que las facultades discrecionales son aquellas en las cuales el órgano autor del acto administrativo puede elegir entre dos o más posibilidades igualmente justas, respetando los principios de razonabilidad, buena fe, y si el objeto del acto es adecuado al fin que la norma señala expresa o tácitamente. ${ }^{24}$

\footnotetext{
${ }^{21}$ Instituto De Investigaciones Jurídicas-unam, Enciclopedia Furídica Mexicana, tomo 4, 2a ed., México, Porrúa, 2004, p. 14.

${ }^{22}$ Acosta Romero, Miguel, Teoría General del Derecho Administrativo. Primer Curso, $17^{\text {a }}$ ed., México, Porrúa, 2004, p. 1113.

${ }^{23}$ Fraga, Gabino, Derecho Administrativo, 42a ed., México, Porrúa, 2002, p. 232.

${ }^{24}$ Alemán Pardo, María José, "Acerca de las diferencias entre discrecionalidad y arbitrariedad en la
} 
Con lo anterior queda más claro que, en determinados casos, aun cuando la norma le da al funcionario la facultad de actuar bajo su criterio, tiene que observar ciertos principios para evitar que su actuar sea contrario a la ley y así preservar el interés público y, consecuentemente, la paz social. La decisión que tome deberá ser acotada en ley y adecuada al caso concreto que se le presente, pues de lo contrario el acto carecería de legalidad y sería arbitrario.

La misma autora observa que se está ante una potestad discrecional cuando la ley no señala, de manera detallada, cuales son las condiciones del ejercicio de la potestad administrativa y deja que el funcionario u órgano envestido del poder complete la condición de su ejercicio; es decir, el objeto y la causa o supuesto que determinan su actuación pueden ser determinados por el agente para que subjetivamente los complete; así, tendrá la libertad de decidir cuándo debe actuar y, si lo hace, qué medidas debe tomar. ${ }^{25}$ Lo anterior constituye una característica de los actos discrecionales, ya que el margen de decisión del órgano es el que exige que se justifiquen las razones de la elección de la autoridad u órgano que ejecuta el acto.

Lo anterior apunta a que la administración manifiesta su voluntad, atendiendo a los presupuestos de hecho que configuran la causa de su actuación; por lo tanto, ésta debe ceñirse a determinados límites en relación con la comprobación de los presupuestos de hecho de los actos, en relación con la certeza y calificación de los mismos. ${ }^{26}$

Para satisfacer estas necesidades, las autoridades están obligadas a actuar en el marco de la ley. La discrecionalidad que caracteriza las normas que la autoridad aplica supone un ámbito de libertad para que la administración elija una solución aplicable al caso concreto. En esta tesitura, una potestad discrecional no está predeterminada por la norma, pues existe una libertad que le permite a la administración elegir entre "actuar" o "no actuar", a lo que el autor denomina "discrecionalidad de actuación", mientras que en los supuestos donde el órgano tienen una libertad de opción para elegir la solución entre varias alternativas igualmente justas, se le denomina "discrecionalidad de elección".27

$\mathrm{Al}$ respecto, la Suprema Corte de Justicia de la Nación se ha pronunciado a través de una tesis asilada, ${ }^{28}$ señalando en lo conducente que en el

actuación de la administración”, Revista de la Fundación Mariano Ruiz Funes, Murcia, núm. 24, año 1997, pp. 109-121. [Consulta: 23 de julio de 2014]. Disponible en: http://goo.gl/cVxOlw

${ }^{25}$ Ibidem, p. 29.

${ }^{26}$ BREwer-Carias, Allan R., Notas sobre la discrecionalidad administrativa, y sobre su delimitación y sus límites. [Consulta: 15 de junio de 2014]. Disponible en: http://goo.gl/3vlrv

${ }^{27}$ Cassagne, Juan Carlos, La discrecionalidad administrativa. [Consulta: 30 de junio de 2014]. Disponible en: http://goo.gl/KlZMId

${ }^{28}$ FACULTAD POTESTATIVA O DISGRECIONAL. En un régimen de derecho, la facultad potestativa o discrecional que confieren las leyes está subordinada a la regla general establecida por el 
sistema jurídico mexicano las facultades discrecionales de la administración, también llamadas potestativas, deberán ajustarse a los requisitos que el artículo 16 constitucional establece para cualquier acto de autoridad, que son fundamentación y motivación. El criterio de referencia señala que las facultades discrecionales deberán respetar el principio de igualdad de los individuos ante la ley, de forma tal que, ante dos circunstancias de hecho y de derecho semejantes, la autoridad se conduzca de la misma forma, pues de lo contrario se estaría ante un acto arbitrario y contrario al principio de legalidad. Razonamiento interesante, pues, en materia tributaria, dificilmente (casi imposible) la circunstancia de un contribuyente ante el fisco, respecto de la naturaleza de su adeudo y su capacidad de pago, será semejante a la de otro contribuyente; de tal suerte que si la ley no es estricta dará lugar a la arbitrariedad.

En el mismo sentido, el máximo Tribunal Constitucional de nuestro país ha señalado, en diversas tesis, ${ }^{29}$ que si el ejercicio de una facultad discrecional

artículo 16 constitucional, en cuanto este precepto impone al Estado la ineludible obligación de fundar y motivar los actos que puedan traducirse en una molestia en la posesión y derechos de los particulares. Cuando una ley establece que la administración puede hacer o abstenerse de hacer un acto que beneficie a un particular, guiándose para su decisión por las exigencias del interés público, esta facultad discrecional debe ejercitarse en forma tal que se respete el principio de igualdad de los individuos ante la ley. De manera que si las circunstancias de hecho y de derecho son las mismas en dos casos, la decisión debe ser idéntica para ambos; de otro modo, no se trataría de una facultad legítima, sino de un poder arbitrario, incompatible con el régimen de la legalidad. Tomo LxxIII, página 8533. Índice Alfabético. Amparo en revisión 3090/42. "Fomento Industrial y Mercantil", S. A. 4 de septiembre de 1942. Unanimidad de cinco votos. La publicación no menciona el nombre del ponente. Quinta Época, Registro: 326322, Instancia: Segunda Sala, Tesis Aislada, Fuente: Semanario Judicial de la Federación, LXXIII, Materia(s): Constitucional, Tesis, Página: 5523.

${ }^{29}$ FACULTAD DISGREGIONAL DE LAS AUTORIDADES. El ejercicio de la facultad discrecional está subordinado a la regla del artículo 16 de la Constitución Federal, en cuanto ese precepto impone a las autoridades la obligación de fundar y motivar los actos que puedan traducirse en molestias a la posesión y derechos de los particulares; y aunque dicho ejercicio supone un juicio subjetivo del autor del acto, que no puede ni debe substituirse por el criterio del Juez, sí está sujeto al control de este último, por lo menos cuando el juicio subjetivo no es razonable sino arbitrario y caprichoso y cuando es notoriamente injusto o contrario a la equidad, pudiendo admitirse que dicho control es procedente cuando en el referido juicio no se hayan tomado en cuenta las circunstancias de hecho, o sean alteradas injustificadamente, así como en los casos en que el razonamiento sea ilógico o contrario a los principios generales de derecho. Amparo administrativo en revisión 160/52. Negri Ramón P. de. 18 de marzo de 1953. Unanimidad de cuatro votos. Ausente: Alfonso Francisco Ramírez. La publicación no menciona el nombre del ponente. Véase: Informe de Labores de 1956, Segunda Sala, página 46, tesis de rubro: "JUICIO SUBJETIVO DE LAS AUTORIDADES ADMINISTRATIVAS. Quinta Época, Registro: 318765, Instancia: Segunda Sala, Tesis Aislada, Fuente: Semanario Judicial de la Federación CXV, Materia(s): Común, Página: 486.

Facultad discrecional de las autoridades. El ejercicio de la facultad discrecional que tengan las autoridades queda sujeta a control en los casos en que el juicio subjetivo en que se funden sea arbitrario, caprichoso, notoriamente injusto o contrario a la equidad; puede añadirse también que dicho control es procedente cuando en tal juicio subjetivo no se hayan tomado en cuenta las circunstancias de hecho o sean alteradas injustificadamente, así como en los casos en que el razonamiento sea ilógico o viole los principios generales del derecho. Amparo administrativo en revisión 522/51. Central Michoacana de Azúcar, S. A. 5 de noviembre de 1951. Unanimidad de cinco votos. Relator: Nicéforo Guerrero. Quinta Época, Registro: 319162, Instancia: Segunda Sala, Tesis Aislada, Fuente: Semanario Judicial de la Federación CX, Materia(s): Administrativa, Página: 1007. 
supone un juicio subjetivo del autor del acto, sí está sujeto al control de un juez cuando el juicio subjetivo no es razonable sino arbitrario y caprichoso y cuando es notoriamente injusto o contrario a la equidad, pudiendo admitirse que dicho control es procedente cuando en el referido juicio no se hayan tomado en cuenta las circunstancias de hecho, o sean alteradas injustificadamente, así como en los casos en que el razonamiento sea ilógico o contrario a los principios generales de derecho. Sin embargo, dichos actos subjetivos de autoridad se pueden declarar ilegales hasta el momento que son sujetos de control jurisdiccional, esto es, al momento en que son controvertidos y no antes: al momento de realizarse el acto mismo.

A pesar de que la característica de discrecionalidad de las facultades y actos administrativos lleve implícita que la libertad de actuación de la autoridad que los ejecuta, no puede ir más allá de lo que la ley establece. La discrecionalidad consiste en que la autoridad tiene la libertad de actuar o no con apego a la ley sin hacer una valoración o imprimir un tinte personal a la facultad que está materializando.

Juan Francisco P. Ibarra argumenta que los actos de los órganos administrativos son discrecionales cuando la ley les otorga una libertad parcial para que la autoridad decida entre dos o más alternativas igualmente justas en miras del interés público. Aún en las facultades que le dan vida a este tipo de actos, la ley no señala exhaustivamente las condiciones del ejercicio de la potestad administrativa; por lo tanto, el órgano puede completar la condición de su ejercicio. ${ }^{30}$

Como se puede observar, las facultades discrecionales atienden a la libertad que tiene la autoridad para elegir entre dos o más posibles opciones. Cuando esto sucede, el funcionario público aplica su criterio para hacer una apreciación de la opción que resulte más favorable para la autoridad. A pesar de que un acto discrecional implique una libertad de apreciación, este tiene que respetar los principios constitucionales que a continuación se mencionan, mismos que constituyen un límite para que estos no se vuelvan arbitrarios:

a) Fundamentación.- Requisito constitucional del acto administrativo que implica indicar con precisión qué ley o leyes y cuáles de sus artículos son aplicables al caso y originan o justifican su emisión. La fundamentación se refiere tanto al contenido del acto como a la competencia del órgano y las facultades del servidor público.

b) Legalidad.- Requisito constitucional del acto administrativo que implica que toda la actividad del Estado, ya sea función administrativa, jurisdiccional o legislativa, debe ajustarse a la ley. Así, los actos han de

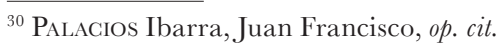


ser producidos conforme a disposiciones previamente emitidas por el legislador. El principio de legalidad refiere que todos los actos administrativos se reputan válidos o legítimos, y corresponde, en todo caso, al gobernado o a los medios de control, demostrar lo contrario.

Si la administración no aplica las funciones que la ley le señala y emplea la voluntad subjetiva, va más allá del objeto que persigue y, en consecuencia, el acto se vuelve ilegal e improcedente, puesto que no atiende a los fines del Estado, contenidos en la norma jurídica, y afecta a los gobernados.

El Segundo Tribunal Colegiado del Decimo Circuito, respecto a las diferencias de las facultades discrecionales y regladas, ha sostenido en tesis aislada que "Para determinar si la autoridad goza de facultades discrecionales o regladas debe atenderse al contenido de la norma legal que las confiere. Si ésta prevé una hipótesis de hecho ante la cual la autoridad puede aplicar o no la consecuencia de derecho prevista en la misma, según su prudente arbitrio, debe afirmarse que la autoridad goza de facultades discrecionales. Empero, cuando la autoridad se encuentra vinculada por el dispositivo de la ley a actuar en cierto sentido sin que exista la posibilidad de determinar libremente el contenido de su posible actuación, debe concluirse que la autoridad no goza de facultades discrecionales sino regladas". 31

Tenemos, pues, que el acto discrecional tiene lugar cuando la ley deja a la autoridad un poder para decidir si debe actuar o abstenerse según su prudente arbitrio. Es la misma ley quien le establece límites en relación con la certeza de los mismos. Ahora bien, en el embargo en materia fiscal, si bien es un acto reglado, el hecho de que el texto de la norma permita o de a la autoridad, específicamente al ejecutor, la posibilidad de actuar a su juicio, no significa que "la ley establece límites claros", por lo que no estamos ante una facultad discrecional.

\subsection{ACTOS ARBITRARIOS}

El actuar de la autoridad en el embargo en materia tributaria que afecta los intereses de los particulares de una manera "apegada a derecho" debe tener una explicación que vaya más allá de ser un hecho contemplado en la ley que no admite más que obediencia por parte de los contribuyentes. Veamos si, en este sentido, el concepto de arbitrariedad nos da respuestas.

El Diccionario Enciclopédico de Derecho Usual indica que la palabra arbitrariedad deriva de arbitrario, que significa "Acto, conducta, proceder contrario

\footnotetext{
${ }^{31}$ Facultad potestativa o discrecional. Semanario fudicial de la Federación y su Gaceta, tomo 17, México, scjN, Quinta Época, Febrero, 2003, p. 1063.
} 
a lo justo razonable o legal, inspirado sólo por la voluntad, el capricho o un propósito maligno, con abuso de poder, fuerza, facultades o influjos". 32

El Diccionario del Español de México señala que la palabra arbitrario significa "Que se comporta según su voluntad y capricho apartándose de la leyes o normas, o sin tomar en cuenta el respeto debido a los demás". 33

El maestro Miguel S. Marienhoff comenta que la arbitrariedad es una conducta antijurídica e ilegítima de los órganos del estado; "siempre el poder arbitrario representa la voluntad personal del titular de un órgano administrativo que obra impulsado por sus pasiones, caprichos o sus preferencias [...] Y es por esta razón que una orden arbitraria carece de todo fundamento legal". ${ }^{34}$

Si tomamos en cuenta que la arbitrariedad es una forma de proceder contraria a la ley e inspirada por una facultad y un capricho de la autoridad, tenemos que el embargo en materia fiscal, en cuanto a la manera en la que actúa el juicio del ejecutor, no encuadra con el concepto de abuso de poder; el hecho de que en determinados casos el ejecutor actúe a su juicio no es contrario a la ley, pues esta misma lo faculta para que actúe de tal modo, por consiguiente, es un acto reglado y deja de lado la posibilidad de que se trate de un capricho.

\subsection{Desvío de poder}

Dentro del tema analizado, otra vertiente consiste en analizar si la actuación de la autoridad fiscal, si bien es legal al estar regulada, puede tener un mal uso de la ley que pueda implicar otra cosa, y tener distintos alcances como el desvió de poder.

Ejercer una facultad legal por parte de la autoridad tiene como límite atender a los fines o consecuencias para los cuales fue concedida y que se encuentran determinadas en la ley; el no actuar en concordancia puede llevar a la autoridad a un desvío de poder.

La doctrina francesa sostiene que el desvío de poder aparece cuando se persigue un fin que no es aquel que se debía perseguir, pues el órgano administrativo obedece a un motivo distinto del que, conforme al sentido implícito de la ley, debió tomar en cuenta. ${ }^{35}$

La desviación de poder es la respuesta ante un positivismo jurídico que es incapaz de dar cuenta del control de la discrecionalidad. Es así que acoge la noción de "ordenamiento jurídico" propuesto

\footnotetext{
${ }^{32}$ Cabanellas, Guillermo, Diccionario Enciclopédico de Derecho Usual, $28^{\mathrm{a}}$ ed., México, Editorial Heliasta, 2003, p. 352.

${ }^{33}$ Diccionario del Español de México, México, El Colegio de México, 2010, p. 237.

${ }^{34}$ Díaz Córdova, Roberto (et. al.), Problemas Actuales del Derecho Fiscal Mexicano, México, Editorial Porrúa, 2006 , p. 64.

${ }^{35}$ Ibidem, p. 67. 
por Santi Romano que concibe al derecho como ordenamiento e incluye las ideas de función o de fin y de unidad entre los elementos que lo componen, siendo las normas o reglas, los medios [sic.] mediante los que se cumplen los fines de la institución; dicho en otras palabras, se considera al derecho en un doble plano: el de las reglas y el de los principios. ${ }^{36}$

Este principio se extiende a cuestionar casos en que la autoridad no guarde sujeción a la ley o a la prueba, o razona falsamente, con lo cual el acto se funda en una sola voluntad, en su capricho personal, aparece la arbitrariedad como vicio de la voluntad. ${ }^{37}$

Por ello, y con base en la opinión de María Isabel Urrutia Cárdenas, pensamos que el desvío de poder es "un vicio del acto administrativo emanado por la autoridad legalmente capacitada para ello, que no consiguió los fines previstos en la ley, o que si ésta no los preveía, el funcionario al hacer uso de sus facultades discrecionales erró en determinar el verdadero espíritu de la ley fundamental o bien concreto no ameritaba la posición del acto dictado". ${ }^{38}$

Recordemos que el Código Fiscal de la Federación le da al ejecutor la facultad de determinar el valor de bienes a embargar para establecer si los bienes señalados para embargo son suficientes o no con relación al adeudo o estime de legales o no los documentos con los que un tercero, al momento del embargo, alega que los bienes son de su propiedad y no del deudor.

En ese sentido, mientras el ejecutor actúe a su juicio, no obra en desvío de poder, pues está procediendo con los fines y consecuencias (sin límites) que le fue concedida en la ley. Por consecuencia, no es cuestionable que estemos ante un capricho personal que dé posibilidad a una arbitrariedad; sin embargo, el problema persiste: la norma le da al ejecutor facultades ilimitadas.

\section{LA INDEFINICIÓN DEL ACTO}

\subsection{La subjetividad del ejecutor en el embargo}

Determinar el tipo de facultad jurídica que lleva a cabo el ejecutor en el embargo al momento en que actúa a su juicio no resulta sencillo, pues parece una facultad que si bien está en la ley (CFF), es sui generis. Que la autoridad fiscal afecte el patrimonio de un particular, en una gestión de cobro a su juicio, parece un actuar subjetivo ilimitado; veamos si esto es así.

\footnotetext{
${ }^{36}$ Tron Petit, Jean Claude, La Nulidad de los Actos Administrativos, 3ª ed., México, Porrúa, 2009, p. 307.

${ }^{37}$ Ibidem., p. 309.

${ }^{38}$ Díaz Córdova, Roberto, et al., op. cit., p. 68.
} 
Según el Diccionario de Latín, ${ }^{39}$ la palabra subjetivo, se escribe subjetive, que deriva de subjetious, y significa: de un modo dependiente del sujeto.

En relación con este término, el Diccionario de Psicología tiene varias acepciones, de entre las cuales podemos destacar las siguientes: que depende del organismo individual; que no admite registro por instrumentos físicos; no susceptible de comprobación por otros investigadores; localizado en el espacio psicológico dentro del cuerpo del observador (por ejemplo Sentimientos, en contr. a la mayoría de los datos visuales, etcétera). [En psicología, el término datos subjetivos y otros semejantes se usan en distintos sentidos según el autor que los emplea, y con frecuencia sin discernirlos de modo preciso. Contr. a datos objetivos. Cf. Objetivo. $]^{40}$

En el ámbito filosófico, subjetivo se refiere al carácter de todos los fenómenos psíquicos en cuanto a fenómenos de conciencia, o sea, tales que el sujeto los refiere a sí mismo y los llama "míos". ${ }^{41}$ A veces también es llamado idealismo psicológico o subjetivismo. Es una teoría del conocimiento según la cual el mundo existe sólo para el espíritu. El único mundo que conocemos es el mundo que conocemos, encerrado en el dominio de las ideas. Ser es percibir, esse est percipii. Esta famosa doctrina llegó a ser la piedra angular del idealismo metafísico moderno. ${ }^{42}$

Filosóficamente, subjetivo (1) puede significar, ante todo, existente de parte del sujeto, oponiéndose a objetivo, existente de parte del objeto. La acepción filosófica más importante (2) es la de no fundado en el objeto, sino condicionado únicamente por sentimientos o afirmaciones arbitrarias del sujeto (recuérdese la certeza puramente subjetiva). ${ }^{43}$

Como se ha comentado con anterioridad, el juicio del ejecutor es un acto de relacionar dos conceptos, donde la fe juega un papel importante; así mismo, incluye aspectos de apreciación y valoración.

En ese sentido, estamos ante un acto subjetivo de autoridad, porque en el momento en que el ejecutor actúa a su juicio, el acto depende del sujeto, no admite, ni la ley lo exige, algún registro por instrumentos físicos, la forma de medición y valoración de los bienes a embargar o documentos a considerar. Se encuentra en el espacio psicológico del observador y, en el momento de la diligencia de embargo, depende de los sentimientos del ejecutor (enojo, aprobación o desaprobación) para determinar la suficiencia de los bienes del patrimonio del deudor que va a embargar o la validez de los documentos

\footnotetext{
${ }^{39}$ De Miguel, Raimundo, Nuevo diccionario latino-español etimológico, $2^{\text {a }}$ ed., Madrid, Visor Libros, Runes, 2013, p. 891.

${ }^{40}$ Warren, Howard C. (compl.), Diccionario de psicología, $3^{\text {a }}$ ed., México, Fondo de Cultura Económica, 2010 , p. 342.

${ }^{41}$ Abbagnano, Nicola, Diccionario de filosofía, $2^{a}$ ed., 8 reimp., México, Fondo de Cultura Económica, 1991, p. 1097.

${ }^{42}$ D. Runes, Dagobert, op. cit., p. 356.

${ }^{43}$ Brugger, Walter, Diccionario de filosofia, 13ª ed., Barcelona, Herder, 1995. p. 523.
} 
que acrediten la propiedad de los bienes de un tercero, pues no tiene límites legales al ser un juicio subjetivo.

\subsection{Los conceptos juridicos indeterminados}

La conceptos jurídicos indeterminados parecen ser un paso importante hacia la solución de lo planteado en la presente investigación, pues a pesar de los distintos enfoques jurídicos estudiados, existe una indefinición jurídica de la actividad que realiza el ejecutor en un embargo cuando determina circunstancias de suma importancia para embargar el patrimonio del contribuyente o de un tercero. De lo visto hasta aquí, parece ser que el ejecutor hace uso de un subjetivismo sin límites y sin sustento técnico en perjuicio de los particulares; sin embargo, los conceptos jurídicos indeterminados nos dan una perspectiva diferente del asunto.

Doctrinariamente los conceptos jurídicos indeterminados se entenderán como aquellos que "por su referencia a la realidad [...] la ley refiere una esfera de realidad cuyos límites no aparecen bien precisados en su enunciado, no obstante es claro que se intenta delimitar un supuesto concreto. La ley no determina con exactitud los límites de esos conceptos porque se trata de conceptos que no admiten una cuantificación o determinación rigurosa, pero en todo caso es manifiesto que se está refiriendo a un supuesto de la realidad que, no obstante la indeterminación del concepto, admite ser precisado en el momento de la aplicación. ${ }^{44}$

Gordillo deja en claro que al final la justicia será la encargada de determinar si se aplicó el concepto jurídico indeterminado de forma correcta. Los conceptos jurídicos indeterminados son una aplicación de lo reglado, es decir, de la ley que crea a este concepto; de ahí que correspondería al órgano judicial subsumir una categoría legal (configurada, no obstante su imprecisión de límites, con la intención de acotar un supuesto concreto). Asimismo, considera, en el caso de los conceptos jurídicos indeterminados, que el control eficaz y válido es el jurisdiccional porque tiene la última decisión y se trata de aplicación de la norma (no delimitada en su forma, pero sí en su fondo). ${ }^{45}$

\footnotetext{
${ }^{44}$ Pozas, Mario A., "Conceptos Jurídicos Indeterminados-CARAVE”. Sitio de consulta y apoyo para el Curso de Derecho Administrativo de la Universidad Centroamericana José Simeón Cañas, El Salvador, 2008. [Consulta: 29 de julio de 2014]. Disponible en: http://goo.gl/utz2Sd

${ }^{45}$ Idem.
} 
Nos encontramos ante conceptos jurídicos indeterminados cuando la ley define el supuesto de hecho a través de conceptos abstractos que sólo pueden ser concretados en su aplicación práctica, ya sea porque la norma se refiere a una realidad cuyos límites no pueden ser bien precisados en su enunciado, ya que no admite una cuantificación o determinación rigurosa, ${ }^{46}$ o bien por que el legislador ha tomado una decisión consiente de no acotarlos de manera precisa para permitir soluciones acomodadas a las circunstancias. ${ }^{47}$

El Cuarto Tribunal Colegiado en Materia Administrativa del Primer Circuito, respecto de los conceptos jurídicos indeterminados o flexibles, ha señalado lo siguiente: ${ }^{48}$

"Los conceptos jurídicos indeterminados o flexibles, aunque en apariencia carecen de una definición concreta, son peculiares en las leyes que, al ser generales, impersonales y abstractas, tienen que incluir términos universales ante la imposibilidad de un casuismo riguroso." Por tanto, la compleja indeterminación de tales enunciados ha de ser dotada de contenido concreto mediante la aplicación, correlación, calificación y ponderación de los hechos o circunstancias específicas de modo, tiempo y lugar prevalecientes en el momento en que se realice su valoración, y que puedan resultar congruentes con su expresión genérica. Así, esa definición en abstracto, de conceptos laxos o inciertos (precio justo, justicia, autonomía) cuyo contenido puede ser científico, tecnológico, axiológico, económico, político, sociológico o perteneciente a otras disciplinas a las que es menester acudir, adquiere un significado específico, preciso y concreto en presencia de las circunstancias definidas en cada caso particular; esto es, al ser contextualizadas con los hechos del caso, es posible verificar si se obtienen o no los objetivos y fines que deben alcanzar y derivar las consecuencias respectivas, que tomando en cuenta los intereses en conflicto permitan encontrar una solución concreta y práctica, por lo que la aparente vaguedad por falta de una descripción pormenorizada que no detalla los citados medios para una predeterminación a priori del alcance, sentido o contenido limitativo del concepto, es un hecho que puede subsanarse al momento de ser aplicado y no implica dejar en manos de la autoridad la facultad de dictar arbitrariamente la resolución corres-

\footnotetext{
${ }^{46}$ García De Enterria y Fernández T.R., Curso De Derecho Administrativo, vol. I, $15^{\mathrm{a}}$ ed., Navarra, Thomson Civitas, 2011, p. 481.

${ }^{47}$ PARejo Alfonso, haciéndose eco de lo dicho por H.U., Erichsen en Administrar y Juzgar: dos funciones constitucionales distintas y complementarias, Madrid, Tecnos, 1993, p. 279.

${ }^{48}$ Conceptos jurídicos indeterminados o flexibles. La falta de una descripción pormenorizada de los hechos o circunstancias especificas de modo, tiempo y lugar para valorarlos y fijar sus alcance y sentido es un hecho que puede subsanarse al momento de aplicarlos sin que ello implique que la autoridad administrativa pueda dictar sus resoluciones en forma arbitraria. Semanario fudicial de la Federación y su Gaceta, tomo 26, México, scjn, Novena Época, julio, 2007, p. 2742.
} 
pondiente, pues el ejercicio de la función administrativa está sometido al control de las garantías de fundamentación y motivación tanto en los casos de las facultades regladas como en el de aquellas donde ha de hacerse uso del arbitrio o la discreción, explicitando mediante un procedimiento argumentativo por qué los hechos o circunstancias particulares encuadran en la hipótesis normativa que, entonces sí, resulta concretada al momento de subsumir los acontecimientos y motivar de esa manera la decisión, evitando visos de arbitrariedad. ${ }^{49}$

En otro criterio emitido anteriormente por el mismo órgano jurisdiccional, respecto de los conceptos jurídicos indeterminados o flexibles, se ha señalado lo siguiente: $:^{50}$

Definir un concepto jurídico indeterminado puede ser complejo y requerir de una especial valoración, sobre todo cuando el lenguaje empleado en su redacción implique conceptos científicos, tecnológicos, axiológicos, económicos, políticos, sociológicos o de otras disciplinas, pues de suyo requiere acudir a ellas. Frente a tal caso es menester acudir a valores, principios e intereses que resulten compatibles con el fin de los actos administrativos para esclarecer el contenido y alcance de dichos conceptos. Por tanto, la subsunción puede ser discutible y opinable e implica estar en zonas de incertidumbre decisoria o probabilidad que necesariamente conducen a una discrecionalidad cognitiva o de juicio. Sin embargo, tener que sortear tales imprecisiones y vaguedad en la apreciación intelectiva y cognoscitiva no es en realidad un caso de discrecionalidad ni de apreciaciones subjetivas. Efectivamente, al tenor de la intelección de los fines de la norma, aunado a la estimación de valores, políticas, principios e intereses en conflicto, todo ello situado en su contexto e interactuando, se obtiene que la autoridad debe encontrar una solución o respuesta en el caso concreto. Para completar la idea conviene distinguir que los conceptos jurídicos indeterminados pueden ser: a) Conceptos de experiencia que consisten en apreciar hechos; la competencia del Juez es ilimitada; y b) Conceptos de valor donde además de apreciar los hechos, se implican juicios de valor que pueden ser técnicos, por ejemplo, impacto ambiental, interés público, utilidad pública. Ello exige un proceso argumentativo en el que entran en juego valoraciones político-morales vigentes en el medio social, pues sólo así es posible adscribir un significado a los conceptos indeterminados frente a la situación prevaleciente, de suerte que la autoridad debe

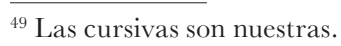

${ }^{50}$ Conceptos jurídicos indeterminados. La forma de actualizarlos al caso concreto exige un proceso argumentativo que debe reducir la discrecionalidad y las apreciaciones subjetivas, eliminando la arbitrariedad. Semanario Judicial de la Federación y su Gaceta, tomo 22, México, scjn, Novena Época, septiembre, 2005, p. 1431.
} 
motivar cómo es que valoró y connotó, hecho y derecho, ya que a pesar de las apariencias se trata de un esquema condicional en el que se debe aplicar la regla a través de la subsunción y asignación de las consecuencias que el fin de la norma exige atender -intención y propósito del sistema normativo-. Asi pues, la teoría de los conceptos jurídicos indeterminados reduce la discrecionalidad administrativa, eliminando la arbitrariedad de todo aquello que deba ser juzgado en términos de legalidad o justicia, pues la interpretación del concepto no necesariamente deriva del tex to de la disposición que lo establece, sino del sentido contextual del ordenamiento. ${ }^{51}$

De ambos criterios podemos inferir que las características de la teoría de los conceptos jurídicos indeterminados son:

- Los conceptos jurídicos carecen de un casuismo riguroso en la ley, y ante ello tienden a incluir términos universales.

- En la aplicación, su indeterminación ha de ser dotada de contenido concreto con base en circunstancias del caso en particular, cuyo contenido está relacionado con disciplinas a las cuales se tiene que acudir.

- Ante la indefinición, se debe de acudir a conocimientos compatibles con el fin del acto administrativo, para esclarecer su contenido y alcances.

- Los conceptos jurídicos indeterminados pueden ser conceptos de experiencia y de valor que exigen un proceso argumentativo; derivado de esa contextualización, se busca una solución concreta y práctica.

- La aparente vaguedad del textojurídico puede subsanarse al momento de ser aplicado, la valoración, connotación hecho y derecho.

- Buscan que, ante las circunstancias, la autoridad no actúe de manera arbitraria.

- Ante el arbitrio o discreción, debe existir un argumento explicativo de los hechos que encuadren en la norma, para evitar la discrecionalidad y arbitrariedad en lo que deba ser juzgado en términos de legalidad o justicia.

- La interpretación de un texto legal deriva del sentido contextual del ordenamiento.

Resulta interesante esta teoría ante la ausencia de precisión de la ley en el caso del embargo fiscal, ya que la falta de definición de conceptos inciertos (como el valor de un bien o la validez de un documento con el que se acredita la propiedad por parte de un tercero) cuyo contenido puede ser perteneciente a otras disciplinas a las que es menester acudir al momento

\footnotetext{
${ }^{51}$ Las cursivas son nuestras.
} 
de las diligencias de embargo. Estos conceptos adquieren un significado específico en presencia de las circunstancias en particular y se hacen valer de condiciones prevalecientes en el momento de la diligencia, de tal forma que no permiten realizar una indebida valoración de los hechos (lo que no ocurriría con expertos en la materia que puedan acudir en el momento de la diligencia a dar su opinión), situación que deberá estar debidamente pormenorizada de manera que encuadren en la hipótesis normativa y el sentido de que se sirvieron para normar el juicio del ejecutor, y evitar la subjetividad infundada, pues es de explorado derecho que los ejecutores, al momento de realizar embargos, encuentran un sinfín de bienes tanto inmuebles con características especiales (ubicación, tamaño, tipo de suelo), como bienes muebles (joyas, pinturas, antigüedades, derechos, valores bursátiles) que requieran de una especial valoración para poder embargar de manera justa aquellos necesarios en relación con el importe del adeudo.

Tener que sortear tales vaguedades por la falta de conocimientos técnicos o especializados para cada caso pone al ejecutor en el plano de la subjetividad infundada en perjuicio del particular, por lo que tratar de dar un valor a las cosas en el contexto en que se encuentre y argumentar tal valoración, ya sea respecto a los bienes indeterminados o al valor de un documento con el cual se acredita la propiedad, tomando en cuenta la situación en su contexto, apreciando los hechos y apoyándose en la oficina exactora para dar en ese momento juicios de valor técnicos, sería una opción para no dejar de atender la intención del sistema normativo, pues la interpretación del concepto no necesariamente deriva del texto de la norma que lo establece, sino del sentido contextual del ordenamiento.

Bajo esas circunstancias, regular la teoría del concepto jurídico indeterminado en materia fiscal federal ayudaría ante la norma legal vigente que permite que, en las diligencias de embargo, se actúe con subjetividad en perjuicio del particular. En este sentido, tendría que adecuarse la normatividad que regula el embargo en atención a los conceptos jurídicos indeterminados, pues la subjetividad es inconstitucional ya que no puede comprender todos los supuestos posibles.

\section{CONCLUSIONES}

Si bien es cierto que entre las tareas más difíciles del Estado se encuentra la de cobrar los adeudos fiscales, existen mecanismos regulados para tal efecto que contienen inconsistencias a favor del particular y también a favor del mismo Estado. A través del procedimiento administrativo de ejecución (PAE), el fisco exige coactivamente el pago de las obligaciones tributarias a los contribuyentes cuando estos no las han cumplido de manera espontánea o cuando lo han hecho fuera de tiempo. 
Uno de los reclamos más recurrentes de los contribuyentes que tienen adeudos fiscales exigibles son los excesos en que incurren los ejecutores (funcionarios encargados de llevar a cabo los embargos por parte de la autoridad fiscal) a la hora de llevar a cabo un embargo con el objeto de garantizar un crédito fiscal u obligar al contribuyente deudor a su pago en ese momento, excesos que en apariencia constituyen un abuso de autoridad.

El Código Fiscal de la Federación permite a los ejecutores la posibilidad de actuar en la etapa de embargo sin límites, cuando vemos que, a su juicio, pueden determinar el valor de los bienes, embargar bienes de uso indispensable del deudor o que formen parte de su actividad ordinaria y determinar la valides de documentos cuando se pretenda acreditar que los bienes son propiedad de un tercero.

En la práctica, es importante no perder de vista que el embargo de bienes se debe de realizar en proporción al importe del crédito fiscal; sin embargo, la ley no le marca límites a esa apreciación.

Respecto a las facultades del ejecutor en el embargo, no podemos decir que son regladas, pues impera para su realización una apreciación personal (subjetiva). Tampoco consideramos estar ante actos discrecionales, pues el hecho de que el texto de la norma permita a la autoridad la posibilidad de actuar a su juicio, no significa que "la ley establezca límites claros". Asimismo, la manera en que actúa el ejecutor no encuadra con el concepto de abuso de poder, pues el hecho de que en determinados casos el ejecutor actúe a su juicio, no es contrario a la ley, sino impulsado por esta última.

En virtud de lo anterior, consideramos que mientras el ejecutor actúe a su juicio, no obra en desvío de poder o arbitrariedad, pues está procediendo con los fines y consecuencias (sin límites) que le fueron concedidos en la ley.

Si lo que se trata de evitar es que el embargo en materia fiscal federal tenga límites legales y se busca una proporción entre lo embargado y el adeudo, una solución al problema es eliminar de la ley el concepto subjetivo de "a juico" y regular la aplicación de la teoría del concepto jurídico indeterminado.

Ante la indeterminación de un concepto en ley, ya no se tendrían que sortear tales vaguedades que ponen al ejecutor en el plano de la subjetividad en perjuicio del particular, pues se daría un valor a las cosas en el contexto en que se encuentre, argumentando tal valoración, tomando en cuenta la situación en su contexto, apreciando los hechos y apoyándose en la oficina exactora para dar en ese momento juicios de valor técnicos, sin dejar de atender la intención del sistema normativo, pues la interpretación del concepto no necesariamente deriva del texto de la norma que lo establece, sino del sentido contextual del ordenamiento.

Sólo así, el embargo en materia fiscal no generaría una incertidumbre jurídica respecto al patrimonio del particular y se practicaría de manera 
objetiva en proporción con lo adeudado, exceptuando los bienes de terceros y los bienes de uso indispensable del deudor para su actividad ordinaria. La subjetividad de la ley se traduce en instrumento de abusos que deja al particular sin elementos para proteger su patrimonio, pues no por tener un adeudo fiscal sus bienes deben quedar al capricho de un funcionario. 
